\title{
El individuo como objeto de amor en Plutarco*
}

\author{
The Individual as an Object of Love in Plutarch
}

\author{
Por: Ezequiel Ludueña* \\ (UBA-UNGS-UCES) \\ Buenos Aires, Argentina \\ Email: eze.ludu@gmail.com
}

Fecha de recepción: 17/02/2019

Fecha de aprobación: 02/04/2019

Resumen: En 1973, en uno de sus célebres trabajos, Gregory Vlastos sostuvo que la doctrina erótica de Platón no admite como objeto central a la persona humana, sino sólo un objeto abstracto - la Idea de la Belleza - muy alejado de los seres de carne y hueso. Por eso, explica, "el afecto personal ocupa un tan bajo puesto en la scala amoris de Platón". Resulta interesante atender a la forma en que Plutarco presenta la doctrina platónica del eros (erōs) en una de sus últimas obras, el diálogo Erótico, una suerte de "comentario" o reflexión sobre el Banquete de Platón. En 2001, John Rist señaló, a propósito de este punto, que para el Plutarco del Erótico, "la belleza que reside en los individuos humanos recuerda y - como el arco iris - refracta la belleza de la Forma (...) pero sólo después de la muerte podremos encontrar realmente esa Forma; mientras tanto debemos también recibir y deleitarnos en la bella propedéutica de los cuerpos hermosos". El eros que sentimos por determinado individuo no exige una superación que implique dejar atrás esa "fase" en aras de un ascenso hacia la Belleza en sí. En el presente trabajo busco profundizar este punto. Para ello, primero resumo el recorrido del diálogo hasta llegar al pasaje en que Plutarco expone la ontología de la belleza individual, sobre el que Rist funda su interpretación. Luego, señalo algunas consecuencias prácticas de esa ontología destinadas a sostener la tesis de que el matrimonio, una relación estable con un único ser, lejos de ser un obstáculo para la práctica filosófica es un medio para llegar a ella. El punto culminante del camino de la Belleza es la relación con una persona en particular, y esa relación

\footnotetext{
* Trabajo realizado en el marco del proyecto PICT 2016-4579, dirigido por la Dra. C. D’Amico. Fondo para la Investigación Científica y Tecnológica (FONCyT) de la Agencia Nacional de Promoción Científica y Tecnológica Período: 2018-2021.

* Doctor en Filosofía por la Universidad de Buenos Aires (Argentina). Docente de Historia de la Filosofía Medieval, Universidad de Buenos Aires, y de Latín, Universidad Nacional de General Sarmiento y Universidad de Ciencias Empresariales y Sociales (Argentina).
} 
supone no una experiencia puntual, una suerte de experiencia mística, sino una continua búsqueda en una relación estable con otro ser humano.

Palabras clave: Plutarco - Erōtikos - Individuo - Erōs - Anaklasis

Abstract: In 1973, in one of his famous papers, Gregory Vlastos contended that Plato's erotic teaching does not admit a human person as its central objects, but only an abstract one -the Form of Beauty- from a different realm far away from beings of flesh and blood. That is why, he argues, "personal affection ranks so low in Plato's scala amoris". It is interesting to pay attention to the manner in which Plutarch presents the Platonic teaching on eros (erōs) in one of his last works, the dialogue Erotikos, a sort of "commentary" -may be just a reflection- on Plato's Symposium. Concerning this issue, in 2001, John Rist pointed out that according to the Erotikos "beauty in visible human individuals recalls and like the rainbow refracts the beauty of Form (...) but only after death will the Form be truly encountered; meanwhile we must also welcome and delight in the propaedeutic beauty in physical bodies". The eros we feel upon certain individual does not imply the same kind of overcoming, i.e. the necessity of leaving behind some provisional stage in order to ascend to the Beauty itself. With this paper I seek to deepen this issue. First, I summarize the dialogue up to the passage in which Plutarch exposes the ontology of individual beauty, the passage from which Rist draws his interpretation. Second, I call the attention to some practical consequences of the ontology of the beautiful as he understands it aimed at stating the thesis that marriage, a stable relationship with another human being, far from being an obstacle to practise philosophy it is an appropriate vehicle to lead a philosophical life. The "last stage" in our journey to Beauty itself is just to deepen a relationship with some particular person. Is not a mystical experience, but a continuous search for process pursued in conversation with another human being.

Key Words: Plutarch - Erōtikos - Individual - Erōs - Anaklasis

\section{Cómo citar este artículo:}

APA: Ludueña, E. (2019). El individuo como objeto de amor en Plutarco. Nuevo Itinerario, 14 (1), 208-227. Recuperado de: (agregar dirección web)

En 1973, Gregory Vlastos publicó un amargo ensayo en el que le reprocha a Platón que su teoría del eros (erōs) no admite como objeto central a la persona 
humana, sino un objeto abstracto - la Idea- muy alejado de los seres de carne y hueso. $^{1}$

Hemos de amar en las personas la «imagen» de la Idea presente en ellas. Hemos de amarlas sólo en tanto y en cuanto son buenas y bellas. (...) Esta es, me parece, la principal falla en la teoría de Platón. No postula un amor por las personas en su integridad... Esta es la razón por la cual el afecto personal ocupa un tan bajo puesto en la scala amoris de Platón. (...) Según esta teoría, hacer de hombres y mujeres de carne y hueso los objetos finales de nuestra afección sería una locura o peor, un acto idólatra, desviar hacia las imágenes lo que sólo es debido a su original divino (Vlastos, 1973, pp. 31-32). ${ }^{2}$

Más allá de lo extraño que resulta hablar de una "falla" (nadie diría que es una falla del olmo no dar peras), la observación parece justa. ${ }^{3}$ Por eso, me parece interesante atender a la forma en que Plutarco presenta la teoría platónica del eros en su diálogo sobre Eros: el Erótico. ${ }^{4}$

Es una de las últimas obras de Plutarco y ha llamado la atención sobre todo por su defensa de la heterosexualidad y del matrimonio como práctica filosófica, por su defensa de la mujer como ser pensante, por postular una relación de cierta

\footnotetext{
${ }^{1}$ Agradezco al evaluador anónimo por sus valiosas indicaciones bibliográficas y de lugares paralelos. Aunque no todo haya sido incorporado, sus observaciones abrieron nuevas y fértiles vías a la presente investigación.

${ }^{2}$ Cf. también los comentarios de Warner que señala que en esta aparente impersonalidad del eros platónico radicaría una de las diferencias entre el Platonismo y el Cristianismo, cuya idea de la visio beatifica implica necesariamente un Dios personal: "Culturas menos individualistas que la nuestra conceden, de hecho, menos centralidad a nociones tales como la de identidad personal. La negación budista del "yo» refleja una clara conciencia de la naturaleza convencional de los criterios utilizados para determinar la identificación y reidentificación de los individuos (...). La interpretación y el valor que nuestra cultura otorga al concepto de "persona» es consecuencia de la tradición cristiana que heredamos..." (Warner, 1979, p. 338).

${ }^{3}$ El juicio de Vlastos parece justo. Pero, como observa Halperin, Platón sí consiguió "crear una teoría erótica que pudiera dar cuenta de la metafísica del deseo" (Halperin, 1998, p. 102). Pues lo que Platón llamó éros no es lo que nosotros llamamos "amor". Halperin anota que si Platón debiera responder a la crítica de Vlastos, de buena gana se apropiaría de estos versos de P. B. Shelley: "I can give not what men call love, / But will thou accept not / The worship the Heart lifts above / And the Heavens reject not, / The desire of the moth for the star, / Of the night for the morrow, / The devotion to something afar / From the sphere of our sorrow?" (To...)

${ }^{4}$ Las referencias son al texto griego de C. Hubert y en la traducción castellana (a menudo modificada) de M. Valverde Sánchez, ambos citados en bibliografía.
} 
13

reciprocidad entre esposo y esposa. Por otra parte, el diálogo ha sido interpretado como una suerte de "comentario", o al menos una reflexión, sobre la doctrina platónica del eros. ${ }^{5}$ Ahora bien, en el final de un prolijo ensayo acerca del sentido antiepicúreo del Erótico, John Rist señala que uno de los puntos en los que Plutarco parece alejarse de Platón es precisamente aquel que perturbaba a Vlastos:

Los estudiosos discuten acerca de si, en la búsqueda platónica de la belleza, el individuo cuya belleza física y del alma han motivado la búsqueda es dejado atrás a medida que el erotikós asciende. (...) Plutarco cree saber la respuesta: la belleza que reside en los individuos humanos recuerda y - como el arco iris - refracta la belleza de la Forma (igual que en el Fedro) pero sólo después de la muerte podremos encontrar realmente esa Forma. Mientras tanto debemos también recibir y deleitarnos en la bella propedéutica de los cuerpos hermosos (Rist, 2001, pp. 574$575)$.

Me interesa profundizar este punto que Rist simplemente apunta. Sintetizaré, entonces, el recorrido del diálogo hasta llegar al pasaje sobre el que Rist funda su interpretación. Luego, señalaré la presencia, en el texto de Plutarco, de algunos ecos del Banquete, que sirven para advertir cuáles son las consecuencias prácticas que se derivan de la ontología de la belleza individual que traza Plutarco y revelan una lectura particular del Fedro y, sobre todo, del Banquete.

Como el Banquete, el Erótico es un diálogo indirecto. Autobulo, hijo de Plutarco, refiere a un grupo de amigos una conversación que su padre mantuvo de joven, cuando, recién casado, peregrinó con su esposa a Tespias. Los padres de Plutarco habían tenido algún tipo de desavenencia con los de su esposa y el joven matrimonio fue a ofrecer un sacrificio a Eros. En Tespias, los recién casados coincidieron con algunos amigos y con los dos personajes que motivan el diálogo: Antemión y Pisias. Estos discuten acaloradamente acerca de la situación de Bacón, un muchacho de unos 18 años del que una mujer de unos 30 años, Ismenedora -viuda,

\footnotetext{
${ }^{5}$ Cf. Rist, 2001, p. 558. Para Dillon (1996, p. 200), "This work is in other respects modelled loosely on the Symposium..."
} 
decorosa, hermosa y pudiente- se ha enamorado. La viuda pretende desposar al muchacho. La madre del joven desconfía; sus amigos se burlan de él a causa de la diferencia de edad. Pisias, uno de los amantes de Bacón (austērotatos tōn erastōn, aclara el narrador) ${ }^{6}$ se opone a la boda. Antemión acusa a Pisias de imitar "a los malos amantes, privando al amigo de una casa, de un matrimonio y de grandes bienes, para que, puro y lozano, se muestre desnudo en las palestras el mayor tiempo posible". ${ }^{7}$ Antemión y Pisias pretenden que Plutarco y sus amigos medien. Entre los amigos de Plutarco, Dafneo defiende la posición de Antemión y Protógenes, la de Pisias.

Se da así una suerte de agón (de hecho, Autobulo observa que la historia “necesita una puesta en escena”): ¿Cuál es el verdadero eros: el que se siente por los muchachos o el que se siente por las mujeres? ${ }^{9}$

En realidad, Protógenes y Pisias entienden que ni siquiera es posible sentir eros por una mujer: la práctica pederasta es espiritual y liberadora; genera amistad y virtud. En cambio, hablar de un eros por las mujeres es absurdo. ${ }^{10}$ Aunque el matrimonio favorece la procreación ( $y$ en este sentido es incentivado por los legisladores), no involucra, ni puede involucrar eros. ${ }^{11}$ Por las mujeres sólo puede sentirse "apetito" (horexis). Todos sabemos que las moscas desean la leche, igual que las abejas desean la miel, pero en ninguno de estos casos hay eros. Algo así ocurre con el deseo que se siente por las mujeres. El fin del deseo es el mero placer, mientras que el eros puede inspirar amistad (philia) y engendrar virtud (aretē). ${ }^{12}$ Ahora bien, sólo por los muchachos podemos sentir eros, es decir, algo más que el mero y pasajero deseo de perfumes y afeites. Es claro: el eros busca jovencitos sedientos de virtud y, cuando los encuentra, conduce sus almas hacia ella mediante la amistad. ${ }^{13}$ Resulta evidente para el lector que Protógenes y Pisias se refieren al eros celeste del Banquete, que Platón introduce con el discurso de Pausanias: para Protógenes y Pisias, el autodominio es la

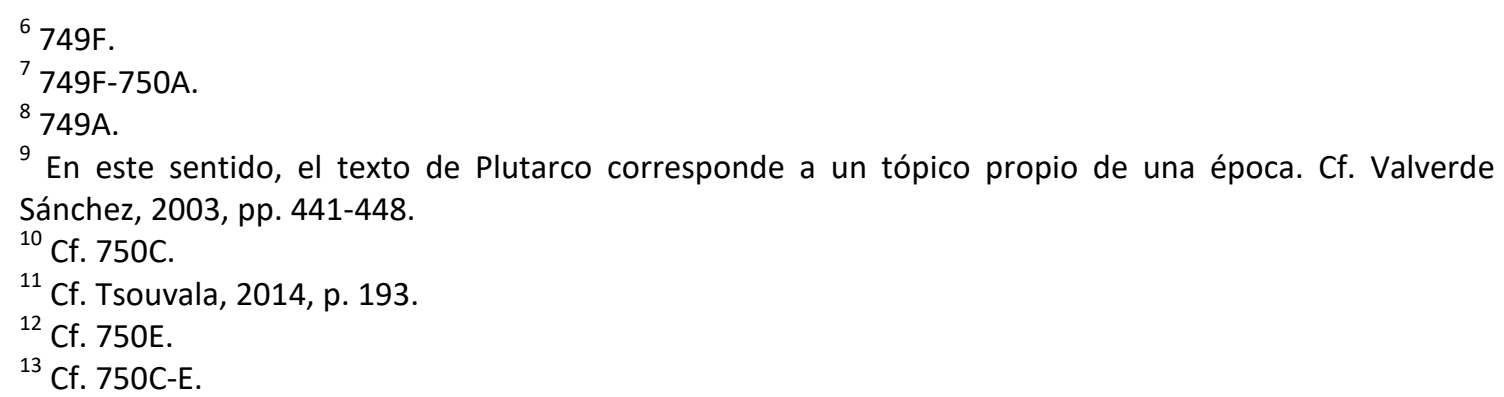


condición de posibilidad misma de la pederastia. Por eso, el eros del pederasta es más noble que el deseo de mujer. El mero deseo de mujer es una simple pulsión animal, y la persecución del placer que le está indisolublemente asociada ata el alma a las voluptuosidades físicas. ${ }^{14} \mathrm{Al}$ verdadero eros, concluye Protógenes, "lo verás sencillo y sobrio en las escuelas filosóficas o tal vez por los gimnasios y palestras a la caza de jóvenes, exhortando a la virtud de forma muy viva y noble". ${ }^{15}$

Antemión y Dafneo defienden la tesis contraria. El único eros genuino es el amor por las mujeres. Y ese otro amor puro que aparentemente sólo se siente por los muchachos es, en la mayoría de los casos, una fachada. Hasta Solón canta la dulzura de los miembros y los suaves labios de los mancebos. Casi siempre, el amante de los muchachos se presenta bajo el disfraz de filósofo, "su pretexto, por tanto, es la amistad y la virtud" pero de noche... "dulce es la cosecha en ausencia del guardián". ${ }^{16}$ Por eso dicen renunciar al placer: por vergüenza y temor. Pues el placer que proporcionan los muchachos es obtenido o "con violencia y rapiña cuando no acceden por su voluntad" o "con molicie y afeminamiento si se entregan voluntariamente contra la naturaleza para ser cubiertos - según la expresión de Platón- como cuadrúpedos", ${ }^{17}$ por eso "es por completo desgraciado, indecoroso y displicente". ${ }^{18}$ Ahora bien, si esto es así, quedan sólo dos opciones: o los placeres sexuales son incompatibles con el eros y la philia y el amante que los obtiene furtivamente no está a su altura o bien, el sexo ha de ocupar un lugar junto al eros y la philia $-\mathrm{y}$ entonces no hay por qué negar la posibilidad de un eros por las mujeres. Para Dafneo, el amor por los muchachos es equivalente a un huracán; el amor heterosexual, en cambio, pone el alma "en una cierta calma", sobre todo cuando se prolonga en el matrimonio, el vínculo "más sagrado"; esa calma es la del matrimonio y la filosofía. ${ }^{19}$

Plutarco toma partido por Dafneo: si el matrimonio es una unión "sin erōs ni philia inspirada por un dios", "a duras penas puede mantenerse bajo el pudor y el

\footnotetext{
${ }^{14}$ Cf. Foucault, 1991, p. 185.

${ }^{15}$ 751A.

$16752 \mathrm{~A}$.

${ }^{17}$ Cf. Fedro $250 \mathrm{E}$ y Leyes I, 636C.

18 751D-E.

${ }^{19}$ Cf. $751 \mathrm{E}$.
} 
miedo sólo con yugos y frenos". ${ }^{20}$ Plutarco se confiesa miembro del coro que defiende el amor conyugal y, por ende, el amor por las mujeres, aun en los casos - como el de Ismenedora- en el que la mujer es mayor:

Si un bebé está sometido a la nodriza, un niño al maestro, un efebo al gimnasiarco, un mancebo a su amante, un hombre adulto a la ley y al estratego, y nadie está libre de autoridad ni es independiente, ¿qué tiene de extraño si una mujer sensata de más edad (gynē noun echousa presbytera) gobierna la vida de un hombre joven, si es beneficiosa por su mayor prudencia (tōi phronein mallon), y dulce y agradable por su afecto (tōi philein)? (754D) $)^{21}$

En este punto el diálogo se interrumpe: como en el teatro, llega un mensajero. $Y$ trae una noticia que indigna a muchos: lejos de guardar su rol de mujer, Ismenedora ha pasado al ataque, ha raptado a Bacón y lo desposará sin el consentimiento de la familia. Protógenes y Pisias corren apresurados para tratar de impedir lo inevitable. ${ }^{22}$ Cuando los misóginos abandonan la escena, surge una conversación de orden teológico, motivada por dos personajes en los que se ha querido ver a dos

\footnotetext{
${ }^{20}$ 752D-E. Cf. Beneker, 2008, p. 692.

${ }^{21}$ La diferencia de edad (a favor de la mujer) es un punto que provoca escándalo entre los misóginos del diálogo. Por eso Plutarco se detiene especialmente en ello: “...los jóvenes son difíciles de unir y conciliar, y apenas al cabo de mucho tiempo deponen su orgullo y su insolencia. Mas al principio se agitan en tormenta y rivalizan con su pareja, y sobre todo si el Amor está presente, como un vendaval en ausencia de timonel, trastorna y arruina el matrimonio, al no ser capaces de mandar ni querer obedecer" (754C). "Although Plutarch does not draw his conclusion explicitly, his implication is clear: by marrying the older widow Ismenodora, Bacchon would gain a wife who already understands - and would be ready to practice - the cooperation required by marriage. If there is to be an erotic dimension, then this sort of stability will be crucial" (Beneker, 2008, p. 690). Plutarco también se refiere a la diferencia de clase (Ismenedora es una viuda rica) a través de la siguiente historia, buen ejemplo del talento narrativo de Plutarco: "Semíramis de Asiria era una sierva, concubina de un esclavo del palacio real. Cuando el gran rey Nino se encontró con ella y se enamoró, hasta tal punto lo dominó y menospreció que le pidió incluso que le permitiera por un solo día sentarse en el trono ciñendo la corona y gobernar. Cuando aquél se lo concedió y ordenó a todos que la sirvieran y obedecieran como a él mismo, dictó con moderación las primeras órdenes, para probar a los guardias. Una vez que observó que a nada se oponían ni vacilaban, ordenó apresar a Nino, luego encadenarlo, y finalmente matarlo. Tras llevar a cabo todo esto, reinó brillantemente en Asia durante mucho tiempo" (753D-E).

${ }^{22}$ Antes de abandonar la escena, Pisias exclama despavorido: “¡Dioses! ¿A qué extremo llegará la libertad que subvierte nuestra ciudad? Gracias al libertinaje (dia tēs autonomias) todo marcha hacia la anarquía (eis anomian). (...) iEntreguemos a las mujeres el gimnasio y la sede del Consejo... si la ciudad está ya totalmente devastada!" (755C). Cf. Georgiadou, 2010-2011, p. 75.
} 
representantes del escepticismo epicúreo: Pémptides y Zeuxipo. ${ }^{23}$ El tema ahora es: ¿Eros es realmente un dios o es una mera pasión humana, que turba la paz del alma y no supone ningún beneficio ${ }^{24}$ El joven Plutarco, futuro sacerdote de Delfos, toma inmediatamente la palabra. Plantear semejante duda atenta contra "la antigua y

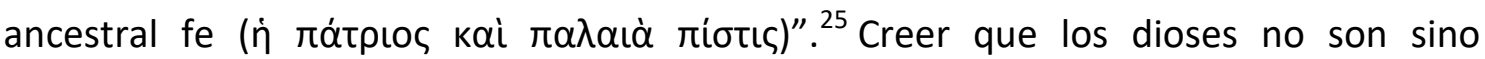

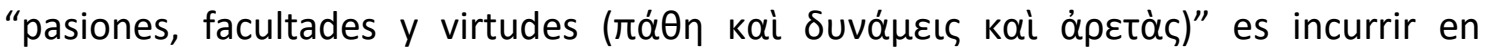
profundo ateísmo. ${ }^{26}$ Plutarco ensaya entonces un discurso sobre el dios Eros. ${ }^{27}$ La fuente de su saber es la "creencia", pues lo que nuestro pensamiento (évvolav) no alcanza por medio de los sentidos puede llegar hasta él como creencia o fe - “desde el principio" manifestada unas veces por el mito, otras por la ley, otras por la razón: iò

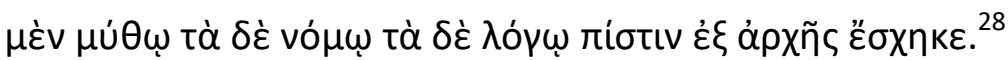

Y es a propósito del testimonio del lógos que el futuro sacerdote de Delfos se refiere, como al pasar, a la doctrina de Platón y las creencias de los antiguos Egipcios. Hay, diseminadas, "algunas sutiles y oscuras emanaciones de la verdad" en la mitología de los Egipcios -señala el personaje Plutarco. ${ }^{29}$ Soclaro le pide luego que desarrolle ese punto, que supone "que el mito de los egipcios coincide con la teoría platónica sobre el Amor". ${ }^{30}$ Plutarco cuenta, entonces, que, "de modo similar a los griegos", los egipcios distinguen entre dos Amores: el Celeste y el Vulgar, retomando así, implícitamente, la célebre distinción del discurso de Pausanias en el Banquete. Pero,

\footnotetext{
${ }^{23}$ Cf. Rist, 2001, pp. 561-562.

${ }^{24}$ Cf. Görgemanns, 2005, pp. 186-188.

25 756B. Me parece correcta la traducción de Valverde: "fe" (más que "creencia") sugiere un conjunto tradicional de creencias más o menos sistematizado. Aunque desde un punto de vista histórico nos parezca inadecuado entender así el entramado doctrinal al que se está remitiendo aquí, entiendo que Plutarco no piensa como nosotros. La intervención del personaje Plutarco se propone justamente aportar a la discusión el punto de vista de una tradición entendida como un sistema orgánico. De allí proviene su autoridad.

${ }^{26} 757 \mathrm{C}$.

${ }^{27}$ En el Erótico, Eros no es un daimōn. Cf. Dillon, 1996, p. 200. Con todo, la idea aparece sugerida en 757E en la protesta de Plutarco: “¿A un hombre que trata de alcanzar... la amistad, ni divinidad ni genio (oute theos oute daimōn) le dirige y le asiste en su empeño?"

${ }^{28} 763 \mathrm{C}$.

${ }^{29} 762 \mathrm{~A}$.

30 764A.
} 
además, los egipcios consideran que el Sol es "un tercer Amor". 31 "Nosotros", afirma Plutarco, advertimos la semejanza. Ambos, Sol y Eros, calientan, pero no con un fuego abrazador "como creen algunos" (los epicúreos, se entiende), sino que el sol calienta los cuerpos y Eros a las almas con un "resplandor y calor dulce y fecundo". ${ }^{32}$ Otra semejanza reside en que así como no cualquiera soporta la luz del sol sin enfermar, no cualquiera resiste la luz de Eros. Pero ello se debe a la propia debilidad. ${ }^{33}$

Sin embargo, hay diferencias. ${ }^{34}$ El sol alumbra tanto lo bello como lo feo; Eros, sólo lo bello. Es más, quizá el sol haga incluso exactamente lo contrario del eros: fija nuestra atención en lo visible, por eso no conduce a buscar nada en ninguna otra parte. Eros, en cambio, es anamnēsis. ${ }^{35}$

Golpeada y hechizada por la luz del sol, el alma olvida, como se olvidan los sueños, las imágenes que ha visto antes de nacer: "sólo a través de los ensueños abraza y admira lo más bello y divino". ${ }^{36}$ Únicamente el divino y prudente Eros, su médico y salvador, puede ayudarla, viajando a través de los cuerpos desde el Hades hacia "el Ilano de la verdad" y eleva a quienes desean (pothountas) abrazar la Belleza pura y sin mezcla. ${ }^{37} \mathrm{Y}$ como Eros se vale de los cuerpos, el alma no puede acceder sólo a aquella región prístina sino a través del cuerpo (dia sōmatos). ${ }^{38}$ Por eso, "el Eros celeste" es una suerte de geómetra: forja bellos reflejos (esoptra) mortales, pasibles y sensibles de bellas realidades divinas, impasibles e inteligibles. ${ }^{39}$ Ante estos reflejos, la memoria "se conmueve (kinei)". ${ }^{40}$

De ahí que en su torpeza algunos, cuyos amigos y familiares trataban de apagar con violencia e irracionalmente (biai kai alogōs) la pasión, no sacaron de ella nada

\footnotetext{
${ }^{31}$ 764B. Afrodita, en cambio, es asociada con la Luna. Sobre este punto y su posterior desarrollo en Isis y Osiris, cf. Brenk, 1988, pp. 462-467 y Rist, 2001, 572-573. Cf. Plutarch, 2006, pp. 166-167, n. 294-298, acerca de las dificultades que supone esta interpretación de la mitología egipcia.

$32764 \mathrm{~B}$.

${ }^{33} 764 \mathrm{C}$.

${ }^{34}$ Cf. Dillon, 1996, p. 201.

${ }^{35}$ Cf. 764E. Con todo, según Brenk (cf. 1988, pp. 461-463), de este pasaje se concluye que, para Plutarco, la mitología egipcia es la clave para entender la doctrina de Platón.

${ }^{36} 764 \mathrm{~F}$.

37 765A.

38 Ibidem.

${ }^{39}$ Cf. 765A-B.

$40765 B$.
} 
provechoso, sino que o se llenaron de humo y turbación, o se consumieron directamente entregados a placeres oscuros e ilícitos (pros hēdonas skotious kai paranomous) (765B).

En cambio, están los que, con prudente reflexión (sōphroni logismō) y moderación (met' aidous), suprimen el furor (to manikon) y dejan sólo el resplandor y ese calor dulce que no genera "una agitación del esperma y una conmoción de los átomos (...), sino una dilatación (diachysin) maravillosa y fecunda, como en una planta que germina y crece". ${ }^{41}$ En poco tiempo, estos traspasan el cuerpo del amado y tocan su èthos - siempre que el amado mantenga en su pensamiento aunque sea una tenue imagen (eidōlon) de lo bello. ${ }^{42}$ Ocurre con la belleza algo parecido a lo que ocurre con el fenómeno del arco iris. Vemos los arco iris como si estuvieran en las nubes. ${ }^{43}$ Hay

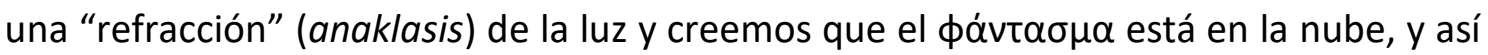
los niños buscan capturar el arco iris con las manos. ${ }^{44}$ Lo mismo ocurre con la belleza, se trata de una ilusión (sophisma); el vulgo busca apresar esos reflejos y sólo obtiene una mezcla de placer y dolor (hēdonēs meminmenēs lypei). ${ }^{45} \mathrm{El}$ amante prudente (sōphronos) sabe que se trata de una refracción. Este parece ser el momento al que se refiere Rist en el texto citado al comienzo: el amante sabe que la belleza del amado es una refracción, pero sabe también que sólo a través de ese reflejo puede entrar en contacto con la Belleza pura. Ahora bien, en rigor, podría decirse que, de alguna manera, no otra cosa se dice en el Banquete o en el Fedro. También allí el amado es el lugar de la belleza (salvo que en el Banquete se habla de la contemplación y del contacto con el mar de lo Bello y se utilizan todos los instrumentos de la via negativa). ${ }^{46}$

Lo último es el fundamento ontológico de la doctrina de Plutarco. Hay una suerte de "refracción". A esto se le suma un punto esencial, que Rist también señala.

\footnotetext{
$41765 C$.

$42765 \mathrm{D}$.

${ }^{43}$ El tratado Isis y Osiris (758F) se dice que, según los mathematikoi, el arco iris es una emphasis del sol. Cf. también La cara visible de la luna 921A.

${ }^{44}$ Cf. 765E-766A.

45 766A.

${ }^{46}$ Cf. Festugière, 1975, p. 227.
} 
En el Erótico, la visión de la Idea o Forma de Belleza sólo es posible post mortem. ${ }^{47}$ Esto significa que, de hecho, el eros que sentimos por determinado individuo no exige una superación que implique dejar atrás esa "fase" en aras de un ascenso hacia la Belleza en sí. ${ }^{48}$ Ahora bien, creo que la originalidad de la enseñanza de Plutarco no queda en la mera exposición de esta ontología de lo bello, sino también en la advertencia de sus consecuencias prácticas. Este punto se relaciona con algunos ecos del Banquete platónico que podemos reconocer en el Erótico.

Hay que fijarse en la respuesta del personaje Plutarco a un comentario de Zeuxipo, perdido en una laguna que ocultan los manuscritos. ${ }^{49}$ De esa respuesta se infiere que Zeuxipo, el epicúreo, considera que el matrimonio sólo es deseable cuando excluye el eros, en cuanto provoca un desorden interior generado por la persecución del acto sexual. Sólo así puede conservarse la ataraxia. ${ }^{50}$ Esto eliminaría la posibilidad de alcanzar cierta calma en una relación heterosexual (si admitimos la hipocresía según la cual entre varones el sexo no tiene lugar). Es decir, según Zeuxipo, el matrimonio es un obstáculo para la práctica de la filosofía. Ante esto, Plutarco advierte que los reflejos de la Belleza $-y$ no sólo los que hallamos en los cuerpos bellospueden provenir tanto de los muchachos como de las mujeres. En la belleza física de las mujeres resplandece "un carácter decente y honesto". ${ }^{51}$ Así,

una vez demostrado que todo es común para los sexos... ${ }^{52}$ luchamos contra aquellos argumentos que Zeuxipo acaba de exponer, identificando al eros con un deseo desordenado y que arrastra el alma hacia el desenfreno (epithymiai ton Erōta tauto poiōn akatastatōi kai pros to akolaston ekpherousēi tēn psychēn), no tanto por estar

\footnotetext{
${ }^{47}$ Cf. 766A-B y Rist, 2001, p. 573. En cambio, cf. Dillon, 1996, p. 201.

${ }^{48}$ Brenk (1988, p. 465) señala el empleo del término agapēton para describir el efecto de la belleza de la persona amada: "se sienten dichosos con el recuerdo y resplandecen de nuevo ante aquella belleza verdaderamente amable, venturosa, querida por todos y deseada (kai makarion kai philion hapasi kai agapēton)..." (765D). Véase, en cambio, el empleo del verbo en el discurso de Diotima: “...para que, finalmente, al fijarse de ahí en más en la variedad de lo bello y ya no sólo en la belleza de un único ser (como un vulgar criado que, negligente y de escaso carácter, contento con la belleza de un único muchachito [agapōn paidariou kallos], de algún hombre o hábito de vida, vive en esclavitud) se vuelva hacia el vasto mar de lo bello..." (210D).

${ }^{49}$ Cf. n. 208 de Valverde a su traducción y Aguilar, 1990, p. 310. Cf. Plutarch, 2006, p. 175, n. 355.

${ }^{50}$ Cf. Beneker, 2008, p. 691.

${ }^{51} 767 \mathrm{~B}$.

${ }^{52}$ Esta sería ya una adquisición de Cínicos y Estoicos. Cf. Gilabert Barberà, 2007, p. 130.
} 
convencido él mismo, sino por haber oído muchas veces a hombres displicentes e insensibles al eros (dyskolōn kai anerastōn) (767C).

Tales hombres reducen a sus compañeras al papel de sórdidas administradoras del hogar, a las que hay que tener siempre sometidas. Y cuando sólo buscan tener hijos o bien "se despiden del matrimonio o, si perdura, no se preocupan de él ni consideran digno amar ni ser amados (oud' axiousin eran oud'erasthai)" ${ }^{53} \mathrm{Y}$ aquí Plutarco introduce un símil clave, sobre el que conviene detenerse. Los varones que sólo quieren procrear - escribe- hacen "como las cigarras que depositan el semen en una cebolla o en algo similar (hōsper hoi tettiges eis skillan è ti toiouto tēn gonēn aphiasin)" y luego se marchan. ${ }^{54}$ La referencia al discurso del Aristófanes platónico es evidente. Como se recordará, en la fábula que ocupa el centro del Banquete, se cuenta que antes de que Zeus inventara el sexo, los seres humanos "no engendraban ni procreaban entre ellos sino en la tierra, como las cigarras (kai etikton ouk eis allēlous all'eis gēn, hōsper hoi tettiges)" ${ }^{55}$ Sólo tras el castigo de Zeus los seres humanos buscan el abrazo de sus antiguas mitades, y el sexo sólo surge cuando Zeus gira hacia el frente los genitales de esas mitades errantes. Antes, nadie necesitaba tocar a nadie para procrear, cada ser era en cierta medida autosuficiente: no necesitaba más que enterrar el semen y marcharse. La pena impuesta por Zeus supone una dependencia. Cada ser, por ser una mitad, depende ahora de alguien más - de sí mismo (i.e. de su otra mitad) o de alguna otra mitad. Es decir, la posición que entiende el sexo como un obstáculo para la práctica filosófica es - al menos en el "actual" estado de las cosasinhumana. Entre otros puntos, el diálogo de Plutarco indica que la filosofía precisa de una relación afectuosa que involucra el sexo, un elemento incluso necesario para que surja el afecto. Plutarco rechaza la autosuficiencia que ve el sexo como un obstáculo que debemos evitar, convirtiéndonos un poco en las cigarras de Platón. No es casual que inmediatamente Plutarco vuelva a traer otra imagen del Banquete. Esta vez no

\footnotetext{
$53767 D$.

${ }^{54} 767 \mathrm{D}$.

${ }^{55}$ Banquete 191C. Cf. Plutarch, 2006, p. 178, n. 372; también p. 185, n. 430.
} 
sólo evoca la fábula de Aristófanes, sino también la intervención de Pausanias — para leerla a la luz de la República:

A quien Eros <...> invade e inspira, en primer lugar comprenderá lo mío y lo no mío como en la ciudad de Platón; ${ }^{56}$ pues no se hacen simplemente comunes los bienes de los amigos (koina ta philōn) <y de los amantes>, ${ }^{57}$ sino que, aun separados en sus cuerpos, reúnen con fuerza sus almas y las funden (tas psychas biai synagousi kai syntēkousi), y ni quieren ni creen en ser dos (mēte boulomenoi dy' einai mēte nomizontes) (767D-E). ${ }^{58}$

El ideal de los enamorados de la fábula de Aristófanes es llegar a ser uno. Sólo Hefesto podría cumplir ese deseo si se presentara y dijera: "estoy dispuesto a fundirlos y a hacer de ustedes una única naturaleza (hymas syntēxai kai symphysēsai eis to auto)". ${ }^{59}$ La referencia parece clara, salvo que el verbo que emplea Plutarco (syntēkō) aparece no en el discurso de Aristófanes, sino en el de Pausanias. A diferencia del erastēs vulgar (el que ama "a las mujeres no menos que a los muchachos"), 60 "el amante que busca un carácter virtuoso se queda para toda la vida, porque está unido a algo constante (hate monimōi syntakeis)" ${ }^{61}$ En el texto de Platón, ese "algo constante" es el alma, igual que en el de Plutarco ("reúnen... sus almas y las funden"). Es decir, el eros de la fábula de Aristófanes cumple con el ideal del discurso de Pausanias, que en el diálogo de Plutarco lo adoptan tantos los misóginos Protógenes y Pisias como el epicúreo Zeuxipo, que presenta el acto sexual como anti-filosófico. Esa unidad, como la de la polis, excluye necesariamente la distinción entre lo tuyo y lo mío, es decir, supone cierta igualdad. Así, de pronto, el amante de Plutarco ya no es el simple erastēs, por muy celeste que sea, sino alguien que busca ser uno con otro, tal como ocurre con las "mitades" de Aristófanes, en el que no cabe la diferencia en erastēs y erōmenos. Por eso, el eros conlleva lealtad:

\footnotetext{
${ }^{56}$ República V, 462C.

${ }^{57}$ Sigo aquí a Valverde.

${ }^{58}$ Cf. Plutarch, 2007, p. 179, n. 377.

${ }^{59}$ Banquete 192D-E.

${ }^{60}$ Banquete 181B.

${ }^{61}$ Banquete $183 \mathrm{E}$.
} 
en el eros se da tanta continencia, decoro y lealtad que, incluso si alguna vez alcanza a un alma disoluta, la aparta de los demás amantes (tōn allōn erastōn) recortando su audacia y doblegando su altivez y grosería (to sobaron kai anagōgon), le infunde pudor, silencio y calma, la rodea de un talante decoroso y la hace atenta a un único ser (henos epēkoon epoiēsen) (767E).

Para Plutarco la práctica de la filosofía exige la progresión erōs - aphrodisia philia. Ese proceso lleva tiempo y requiere estabilidad. ${ }^{62}$

eros parece provocar al principio cierta efervescencia y perturbación, mas luego con el tiempo, restablecido y aplacado, presenta la disposición más estable (tēn bebaiotatēn diathesin). Pues ésa es en verdad la así llamada fusión total (hē di' holōn legomenē krasis) de los amantes (hē tōn erōntōn); la de los otros, la de los que sólo comparten una misma casa se parece a los roces y enlaces (tais... haphais kai periplokais) de Epicuro, [sólo] comprende choques y rebotes: no produce una unidad tal como la que produce el eros. (769F)

Por eso, según Plutarco, puede haber sexo sin Eros (se encuentra a la vuelta de la esquina y no es caro), ${ }^{63}$ pero no Eros sin sexo. ${ }^{64}$ Pero la unión del matrimonio, aunque supone el sexo, es algo más, advierte Plutarco. No es pobre amalgama de átomos, como suponen los epicúreos: es krasis $^{65}$ (el resultado del eros "moderado"

\footnotetext{
${ }^{62}$ Cf. Tsouvala, 2014, pp. 202-203.

63 "La obra de Afrodita sin Amor es mercancía de una dracma. (...) Muchos, en efecto, compartieron con otros los placeres sexuales, prostituyendo no sólo a sus concubinas sino también a sus esposas." (759E).

64 "Pues una unión sin eros, igual que el hambre y la sed, tiene como fin la saciedad (plēsmonēn) y no conduce a nada hermoso. Gracias a Eros, la diosa, evitando el hastío del placer, genera afecto y concordia (all' hē theos Erōti ton koron aphairousa tēs hēdonēs philotēta poiei kai synkrasin)" (756E). "Solón fue un legislador muy experto en asuntos matrimoniales al prescribir que el hombre se acerque a la esposa no menos de tres veces al mes, no por placer seguramente, sino queriendo con tal muestra de afecto renovar el matrimonio de las disensiones que siempre se acumulan" (769A). "El amor entre marido y mujer se enriquece mediante la unión sexual. (...) Plutarco otorga así un valor moral a la unión sexual entre los cónyuges, pues hace crecer la amistad, la concordia y la fidelidad mutuas." Valverde Sánchez, 2003, pp. 450-451.

${ }^{65}$ Según Beneker (2008, p. 693), un ejemplo de la cooperación entre mujer y hombre en un matrimonio (o al menos de la relativa igualdad de la mujer respecto del varón) es el episodio de Porcia en la Vida de Bruto: "Bruto... dándose perfecta cuenta de todo el peligro, en público, intentaba contener y ordenar sus pensamientos, pero en casa, durante la noche, no era el mismo. A veces la preocupación lo sacaba, a
} 
según el discurso de Erixímaco). ${ }^{66}$ Lo propio de ella es, pues, otro de los ideales del discurso de Pausanias: la estabilidad. ${ }^{67}$

Como se dijo, Plutarco entiende que sólo luego de la muerte es posible una visión directa de la Belleza. ${ }^{68}$ Por el momento, los cuerpos son lo mejor que tenemos. Acaso por eso, en el largo discurso del joven Plutarco, no hay realmente una scala amoris: hay sólo dos grados claramente diferenciados, el de la belleza física y el de la belleza del carácter, y la primera es un aspecto de la segunda. El resto implica profundizar en la relación con un único ser. Y en ella el sexo es un elemento necesario: no hay oposición entre philia y aphrodisia. ${ }^{69}$

Así, más allá de su intento de reivindicar la monogamia heterosexual, la originalidad de Plutarco parece radicar sobre todo en concebir al individuo (que según

su pesar, del sueño; otras, cuando más imbuido estaba en sus pensamientos y consumido en las preocupaciones, no se le escapaba a su mujer, que descansaba a su lado, que se encontraba en medio de una agitación desacostumbrada... Siendo como era Porcia cariñosa, amante de su marido e inteligente, llena de sensatez (noun), no intentó preguntar a su marido sobre sus secretos antes de haberse sometido a la siguiente prueba. Tomando un cuchillito de esos con los que los barberos cortan las uñas... se hizo en el muslo un corte profundo. La sangre fluyó abundante y después de un poco se apoderaron de ella fuertes dolores y temblores febriles a causa de la herida. Bruto estaba angustiado e inquieto. Entonces, ella, en el punto más alto de su dolor, le habló así: «Yo, Bruto, que soy hija de Catón, fui entregada a tu casa, no como las concubinas, para compartir sólo el lecho y la mesa, sino como compañera de lo bueno y también de lo malo. En el matrimonio tu comportamiento ha sido irreprochable, pero, de mi parte, ¿qué demostración o signo de reconocimiento puedo darte si no se me permite soportar contigo tu sufrimiento secreto ni ese desvelo que exige confianza? Sé que la naturaleza femenina es considerada débil para soportar un secreto. Pero, Bruto, una buena educación y una compañía honrada alguna fuerza tienen sobre el carácter. A mí me cabe ser hija de Catón y mujer de Bruto. Antes no me fiaba demasiado de eso, ahora sé que yo misma puedo ser invencible ante el dolor». Dicho esto le muestra la herida y le explica la prueba. Él, impresionado y levantando los brazos, pidió que los dioses le concedieran éxito en su empresa y poder mostrarse como digno marido de Porcia. Y después se encargó de curar a su esposa" (trad. citada en Bibliografía). Cf. también Valverde Sánchez, 2003, p. 444. Sobre la presencia de las ideas filosóficas de Plutarco en las Vidas paralelas, y la tradición del uso de exempla y la relación entre teoría y práctica en general, cf. Brenk, 2008, (sobre el Erótico, pp. 246-251), Vicente Sánchez (2008), y, sobre todo, Bonazzi (2012) y Warren (2016), pp. 107 y ss. Sobre otros posibles ejemplos de comprender esta krasis entre esposo y esposa, cf. Deberes del matrimonio 139F-140A y 142F-143A. En cuanto al término krasis se corresponde con fuentes estoicas. Cf. Plutarch, 2006, p. 184, n. 423. “Asimismo [Musonio Rufo] considera que el 'afecto' o 'amistad' entre marido y mujer, para quienes todo es común (cuerpo, alma y hacienda), resulta mayor que en cualquier otra relación; y que además el matrimonio es tutelado por la divinidad (Hera, Eros y Afrodita). Plutarco pone el mismo énfasis en la idea de 'comunión' de alma y de cuerpo, superior a otros vínculos afectivos, que representa el matrimonio (770a) bajo la tutela conjunta de Eros y Afrodita (756e; 767d-e; 769f770a). En cualquier caso, tales cuestiones se habían convertido en materia común en el debate filosófico." Valverde Sánchez, 2003, p. 448 y 447.

${ }^{66} \mathrm{Cf}$. Banquete 188A.

${ }^{67}$ Cf. Banquete 182C: hē Harmodiou philia bebaios.

${ }^{68} \mathrm{Cf} .766 \mathrm{~A}-\mathrm{B}$.

${ }^{69}$ Cf. Brenk, 1988, p. 460 y Beneker, 2008, p. 693. 
el texto, debe ser necesariamente una mujer) como objeto principal del eros filosófico en esta vida. ${ }^{70}$

Otra es la cuestión de la naturaleza real de esa krasis, en términos de las relaciones sociales entre los sexos. La mujer puede ser objeto del eros filosófico, ¿’pero puede ser sujeto? La historia de Ismenedora y la defensa que hace Plutarco de su rol de guía (en virtud de su phronēsis) parece indicar que sí. ${ }^{11}$ Pero si atendemos a otros escritos de Plutarco, la presunta igualdad en la búsqueda compartida de la sabiduría en una relación heterosexual se vuelve, para nuestro criterio actual, borrosa. ${ }^{72}$ En los Deberes del matrimonio, se recomienda al joven esposo que practique la filosofía y discuta sobre ello con su mujer para familiarizarla con los discursos filosóficos, para que lea, por ejemplo, a Platón o Jenofonte: "porque para ella -explica Plutarco«eres» el padre "y la venerada madre así como el hermano». Y no menos honroso es

\footnotetext{
${ }^{70}$ Curiosamente, Gilabert Barberà (2007, p. 129) escribe: "Plutarch does not infringe at all the laws of Platonic love but applies common sense to his erotic logos, that is to say, erōs is finally also attributed to gyne, gamos kai ta tekna in accordance with the most elementary logics, which is enemy of the absurd (to atopon). Plutarch, in short, makes a Platonic correction of Plato." No resulta claro cuáles son las "leyes" del amor Platónico, y, por momentos, el autor parece adjudicar a Platón las posturas expuestas en los discursos de Erixímaco y de Agatón, cf. Gilabert Barberà, 2007, p. 126. En un sentido parecido, en otro trabajo el autor adopta una lectura literal del discurso de Pausanias. Cf. Gilabert Barberà, 19881989, pp. 38-39.

${ }^{71}$ Recuérdese el texto citado arriba: “¿qué tiene de extraño si una mujer sensata de más edad (gynē noun echousa presbytera) gobierna la vida de un hombre joven, si es beneficiosa por su mayor prudencia (tōi phronein mallon), y dulce y agradable por su afecto (tōi philein)?" (754D).

72 Cf., en este sentido, Dodds, 1933, p. 100. "Para Plutarco, no obstante, esa armonía conyugal implica cesión por parte de la mujer ante la autoridad del marido, una autoridad moral, eso sí, fundada en el afecto y el respeto mutuos y ejercida de modo justo y benévolo. (...) Plutarco sitúa a la mujer 'prácticamente' en igualdad con el varón, considerándola dotada para la virtud y el amor, y eleva la unión amorosa entre los esposos a la más alta dignidad desde una base filosófica y religiosa." (Valverde Sánchez, 2003, p. 453). Warren, por su parte, advierte: "The changes in social structure during the early Imperial Period afford women more independence. (...) They are no longer simply wives and daughters, but they are benefactors and stratēgoi, doctors and mathematicians. The Woman is therefore able to define her identity in the same way as the Man as either a status-relation to others, or as a sovereignrelation to herself. In becoming the ethical subject of her own actions, psychagogy gives Woman the ability to define her identity on her own terms, and to set the conditions for participation in public life according to her own criteria. According to psychagogic practice, she can only do so by engaging critically with philosophy. There is, however, a difference in the way Plutarch treats the formation of Self in Man and Woman. (...) Plutarch's psychagogy for women does not allow much space for Woman to define her identity in the absence of Man. Her identity, for Plutarch, is fundamentally a status-relation to man in which the formation of a Self that is the ethical subject of its own actions becomes impossible. Woman's identity is fundamentally linked to that of Man, and as a result, Plutarch's psychagogy steers her clearly in this direction." Warren, 2016, pp. 117-118.
} 
oír a tu mujer decir: «Esposo, tú eres para mí guía, filósofo y maestro de las cosas más bellas y divinas»" ${ }^{73}$

Sin embargo, al margen de estas consideraciones, si en el texto de Plutarco quisiéramos encontrar un elemento equivalente a la visión intelectual de la Belleza en sí, a la epopteia del Banquete, ${ }^{74}$ ese elemento sería el matrimonio. Al menos en esta vida, el punto culminante no es la visión de un objeto (por más sui generis que sea), sino la relación con una persona en particular, y esa relación supone no una experiencia puntual, una suerte de experiencia mística, sino una continua búsqueda en una relación estable con otro ser humano. ${ }^{75}$ Sólo entonces, "más que en cualquier otro momento - como diría Diotima-, la vida de un ser humano es digna de ser vivida", cuando dos individuos advierten uno en el otro la ilusión del arco iris, o algo así. En suma, algo más parecido a ese "amor" que, a comienzos de los '70, Vlastos le reclamaba a Platón.

\section{Bibliografía}

Aguilar, R. M. (1990). La mujer, el amor y el matrimonio en la obra de Plutarco. Faventia 12-13. 307-325.

Beneker, J. (2008). Plutarch on the Role of Eros in a Marriage. En A. Nikolaidis (ed.), The Unity of Plutarch's Work: Moralia Themes in the Lives, Features of the Lives in the Moralia (pp. 689-699). Berlin: W. de Gruyter.

Bonazzi, M. (2012). Theoria and Praxis: On Plutarch's Platonism. En T. Bénatouïl y M. Bonazzi (eds), Theoria, Praxis, and the Contemplative Life after Plato and Aristotle (pp. 139-162). Leiden: Brill.

\footnotetext{
${ }^{73}$ Deberes del matrimonio 48, 145B-C. En el comienzo de este opúsculo, se compara la filosofía y sus consideraciones acerca del matrimonio a una suerte de afrodisíaco: "Entre los músicos se le llamaba a uno de los temas convencionales para flauta, hippóthoron, una melodía que, al parecer, despertaba un vivo deseo en los caballos, incitándolos al apareamiento. De las muchas y hermosas consideraciones de las que se ocupa la filosofía, ésta que trata del matrimonio no es, en modo alguno, la que merece menos atención, pues con ella la filosofía ejerce un atractivo sobre los que se han unido en una vida común y los hace afables y afectuosos unos con otros" (138B).

${ }^{74}$ Cf. Rist, 2001, p. 573.

75 "The Platonic ascent toward the Form of the Beautiful as a passive intellectual object has been transformed by Plutarch into the reciprocal love of the soul and its telos, conceived of as both the Form of the Beautiful and a divine person" (Brenk, 1988, 464). En este sentido, uno podría preguntarse en qué consiste el camino si el fin no es una visión intelectual: ¿cuál sería aquí el equivalente de los ponoi del discurso de Diotima?
} 
Brenk, F. E. (1988). Plutarch's Erotikos: The Drag Down Pulled Up. Illinois Classical Studies 13/2. 457-471.

Brenk, F. E. (2008). Setting a Good Exemplum. Case Studies in the Moralia, the Lives as Case Studies. En A. G. Nikolaidis (ed.), The Unity of Plutarch's Work: 'Moralia' Themes in the 'Lives', Features of the 'Lives' in the 'Moralia' (pp. 237-253). Berlin/New York: Walter de Gruyter.

Dillon, J. (1996). Plutarch of Chaeroneia and the Origins of Second-Century Platonism. En J. Dillon, The Middle Platonists (pp. 184-230). Ithaca: Cornell University Press. Dodds, E. R. (1933). The Portrait of a Greek Gentleman. Greece \& Rome 2/5. 97-107. Festugière, A. J. (1975). Contemplation et vie contemplative selon Platon. Paris: Vrin. Foucault, M. (1991). Historia de la sexualidad. Vol. 3: La inquietud de sí. (T. Segovia, Trad.). Buenos Aires: Siglo XXI.

Georgiadou, A. (2010-2011). Playing with Intertexts in Plutarch's Erotikos. Illinois Classical Studies 35-36. 69-84.

Gilabert Barberà, P. (2007). Love in Plutarch: The Necessary Platonic Correction of Plato. En AA.VV., El amor en Plutarco. Actas del IX Simposio Internacional de la Sociedad Española de Plutarquistas (pp. 123-132), León: Universidad de León, Secretariado de Publicaciones y Medios Audiovisuales.

Gilabert Barberà, P. (2008). Algunas reflexiones críticas sobre la lectura de Michel Foucault del Erótico (Amatorius) de Plutarco. Universitas Tarraconensis XII (19881989). 37-49

Görgemanns, H. (2005). Eros als Gott in Plutarchs Amatorius. En R. Hirsch-Luipold (ed.). Gott und die Götter bei Plutarch (pp. 169-195). Berlin/New York: Walter de Gruyter. Halperin, D. M. (1998). Platonic Erôs and What Men Call Love. En N. D. Smith (ed.), Plato: critical Assessments, vol. III (pp. 66-120). London: Routledge.

Platón. (2015). Banquete. (E. Ludueña, Trad.). Buenos Aires: Colihue.

Plutarch. (2006). Dialog über die Liebe. (W. G. Jeanrond, H. Görgemanns, B. Feichtinger, F. Graf, J. Opsomer, Trads.). Tübingen: Mohr Siebeck.

Plutarchus. (1971). Amatorius. En C. Hubert (ed.), Moralia, vol. IV (pp. 336-396). Leipzig: Teubner. 
Plutarco. (1986), Deberes del matrimonio. En Obras de morales y de costumbres, vol. II (pp. 177-205). (C. Morales Otal y J. García López, Trad.). Madrid: Gredos.

Plutarco. (2003). Erótico. En Plutarco, Obras de morales y de costumbres, vol. X (pp. 41123). (M. Valverde Sánchez, Trad.). Madrid: Gredos.

Plutarco. (2009). Bruto. En Plutarco, Vidas paralelas, vol. VII (pp. 333-395). (M. González González Trad.). Madrid: Gredos.

Rist, J. M. (2001). Plutarch's Amatorius: A Commentary on Plato's Theories of Love?. Classical Quarterly 51/2. 557-575.

Tsouvala, G. (2014). Love and Marriage. En M. Beck (ed.), A Companion to Plutarch (pp. 191-206). Hoboken: Wiley \& Sons.

Valverde Sánchez, M. (2003). Amor y matrimonio en el Erótico de Plutarco. En J. M. Nieto Ibáñez (coord.), Lógos hellenikós: homenaje al profesor Gaspar Morocho Gayo Vol. 1 (pp. 441-455). León: Universidad de León, Secretariado de Publicaciones y Medios Audiovisuales.

Vicente Sánchez, A. (2008). Plutarco compositor de Vitae y Moralia: analisis intratextual. En A. G. Nikolaidis (ed.), The Unity of Plutarch's Work: 'Moralia' Themes in the 'Lives', Features of the 'Lives' in the 'Moralia' (pp. 209-217). Berlin/New York: Walter de Gruyter.

Vlastos, G. (1973). The Individual as an Object of Love in Plato's Dialogues. En G. Vlastos, G., Platonic Studies (pp. 3-42). Princeton: Princeton University Press.

Warner, M. (1979). Love, Self and Plato's Symposium. The Philosophical Quarterly 29/117. 329-339.

Warren, L. (2016). Psychagogy in Plutarch's Moralia and Parallel Lives: the image of the ideal Woman. Tesis doctoral presentada en la Stellenbosch University (Sudáfrica). 